[Jpn. J. Agric. Econ. Vol.23, pp.113-118, 2021]

\title{
Exploring Corporation-Cooperative Arrangements in Agricultural Value Chains: The Case of Madagascar Vanilla
}

\section{Tsilavo Ralandison ${ }^{1}$}

This paper explores newly established corporation-cooperative arrangements in Madagascar's vanilla sector. It presents findings on how these arrangements are primarily driven by downstream lead firms seeking to secure access to high quality produce. These arrangements are part of corporations' interests in developing new sourcing channels and pursuing explicit coordination strategies by integrating farmers into their value chains. Against a backdrop where international and national actors have been promoting cooperatives in the agricultural export sector in developing countries, this contribution suggests that these arrangements should be brought to light and closely evaluated.

Keywords: producer organization, contract farming, Africa

\section{Introduction}

Since the 1990s, agribusiness corporations have been creating and partnering with agricultural producer cooperatives (hereinafter "coop") that handle export cash crops in developing countries. For example, Cargill, one of the largest agricultural commodity houses, claims to source 99\% of its cocoa from coops in Côte d'Ivoire as of 2016. ${ }^{1)}$ This process has been described in the agricultural development and commodity chain literature as vertical coordination by lead firms to integrate farmers in their value chains. This type of direct sourcing model tends to include contract farming arrangements (CFAs) that can take the form of marketing contracts in which agreements are made on the transaction or production contracts that entail tighter coordination (Gereffi et al., 2005; Barrett et al., 2012). Specifically, in Africa, there has been a push to link smallholder producers with input companies, processing factories or marketing agents (World Bank, 2007). Alongside this, coops in Africa have been championed as a "triple win instrument for rural development" that benefits producers, the state, and international buyers (Wedig, 2019).

While many studies have investigated this process of integration of African smallholders in global value chains via

${ }^{1}$ Graduate School of Economics, Kyoto University

Email: tsilavo@econ.kyoto-u.ac.jp

1) https://www.cargill.com/doc/1432099950824/cargill-cocoapromise-report-2016-17.pdf.

2) International Cooperative Alliance

https://www.ica.coop/en/cooperatives/cooperative-identity accessed on October 2, 2020. In the paper, "cooperative" refers to any kind of cooperative and "coop" is short for agricultural producer cooperative. producer organizations and the spread of CFAs (e.g., Little and Watts, 1994; Gibbon and Ponte, 2005), few have focused on coops within CFAs and how corporations have created coops to be included in a CFA. This might be because coops are treated as one of the several legal forms of producer organizations, with some studies even using the two terms interchangeably (e.g., Wedig, 2019).

Examining these, what I would call corporationcooperative arrangements (CCAs), is significant given how they have emerged and the underlying antagonistic relations that exist. A cooperative is a specific form of organization defined as an autonomous association of persons united to meet their economic, social, and cultural needs and aspirations through a jointly-owned and democraticallycontrolled enterprise. ${ }^{2}$ If a cooperative is initiated by an outside entity, it raises questions about the association's autonomy and members' participation and representation. ${ }^{3)}$ While CCAs may improve farmers' livelihood through the modernization of production, coop members also risk remaining dependent on corporations for credit, the supply of inputs, contracting, and selling. This dependency, coupled with asymmetrical power relations between corporations and coops, may make it challenging for members to meet their

3) Historically, coops in developing countries tend to be initiated by outside actors, such as governments, NGOs, or religious organizations, but not usually multinational corporations. An exception in corporations' direct involvement in coop development includes the banana coops in the Caribbean and Central America in the 19th century (Birchall, 1997). While parallels may exist between then and now, this study is situated in the current context of contract farming and coop development in Africa. 
needs and pursue their aspirations, such as controlling the higher-value processes and activities that happen after production.

To understand what these CCAs entail and how they came about, I focus on recent changes within Madagascar's vanilla sector where several multinational corporations have initiated the development of coops as part of their new direct sourcing strategies. ${ }^{4)}$ Data in this paper is derived from two sets of sources. The first is government statistics, journal articles, books, industry reports, and organizations' websites. The second is my fieldwork in Madagascar in August and September 2019, when interviews were conducted with vanilla farmers, coop leaders and managers, collectors, exporters, importers, NGO representatives, and government officials.

The paper is organized as follows. Section 2 offers an overview of the vanilla chain that draws from the commodity systems approach developed by Friedland et al. (1981). ${ }^{5)}$ Section 3 presents a list of reasons to explain why CCAs have been established. Section 4 discusses the significance of these arrangements and suggests potential areas for future research.

\section{Overview of the Vanilla Chain}

Vanilla is a high-value agricultural commodity. It is one of the world's most popular and most expensive flavors. Less than $1 \%$ of the "vanilla flavor" used in the food industry comes from an entirely natural source: the vanilla orchid. The rest is synthetic vanillin, which is mostly petroleum-based. Vanillin, whether natural or artificial, is mainly used to flavor sweet foods. The ice cream and chocolate industries together make up $75 \%$ of the vanillin market as a flavoring. Madagascar has been the world's leading vanilla supplier, specifically Bourbon vanilla, the food industry's preferred type. ${ }^{6)}$ As in most vanilla producing countries, Madagascar's vanilla is almost entirely exported. In 2017, vanilla represented $26 \%$ of total exports, making it one of the country's top export commodities (OEC, 2019). ${ }^{7}$

\section{1) Labor and production system}

Vanilla production in Madagascar is highly labor-intensive.
The vanilla orchid is grown using traditional cultivation methods without mechanization and minimal agricultural inputs. Producers must properly attend vanilla vines for three to four years before they can harvest beans. Vines can produce beans for six to eight years after the first harvest. During the first two years, crop husbandry, such as pruning and weeding, can involve 260 worker-days per hectare. As the plants mature from the third or the fourth year, as many as 460 worker-days per hectare are needed to ensure that each orchid flower is hand-pollinated (Cadot et al., 2006). Vanilla cultivation in Madagascar is mostly done by smallholder farmers who grow other crops, such as rice, which is the country's staple food. It is estimated that there are 80,000 vanilla farmers and that most of them live in the north-eastern regions of Sava and Analanjirofo (e.g., International Labour Organization, 2012). Transforming green vanilla beans into black cured beans involves weeks of steaming, drying, sorting, and fermenting. Even though cured beans are more lucrative, most farmers only sell green beans, which are highly perishable. Only $5 \%$ of farmers are involved in curing activities as they lack production, skills, and tools (Hänke et al., 2018). Prices received by farmers selling green beans represent roughly $10 \%$ and $5 \%$ of the value paid to exporters and importers, respectively (Figure 1).

\section{2) Marketing and distribution systems}

The main actors in Madagascar's vanilla value chain are farmers, collectors, exporters, international traders, flavor processors, and end-users (i.e., food corporations and retailers). Farmers mainly sell on the spot markets via a network of collectors who can be independent businesses of various scales or exporter's purchasing agents. Exporters are involved primarily in financing post-harvest activities, such as collecting green beans, processing green beans into cured beans, packaging, and shipping. ${ }^{8)}$

Between 1960, when Madagascar's independence was declared, and 1993, the state (via marketing boards and stabilization funds) purchased green vanilla beans from farmers at set prices, marketed them directly, and set export prices (Blarel and Dolinsky, 1994). In terms of exporting,

systems.

6) Most commercial vanilla comes from the vine species vanilla planifolia. It is the Bourbon curing process that produces Bourbon vanilla (Correll, 1952). Madagascar supplies up to $80 \%$ of the world's Bourbon vanilla (Hänke et al., 2018).

7) The Observatory of Economic Complexity https://oec.world/en/ accessed on November 16, 2019.

8) Interviews in Madagascar in August and September 2019.

5) The empirical research is informed by four out of the five foci detailed by Friedland et al., namely production practices, labor as a factor of production, grower organization, and distribution 
there were only a dozen exporters in Madagascar selling to international commodity houses, such as Touton (France) and Aust \& Hachmann (Canada and Germany). At this time, two-thirds of Madagascar's total exports were controlled by three exporters (Cadot et al., 2006). The flavor processors, food corporations, and retailers mainly sourced vanilla from the international commodity houses.
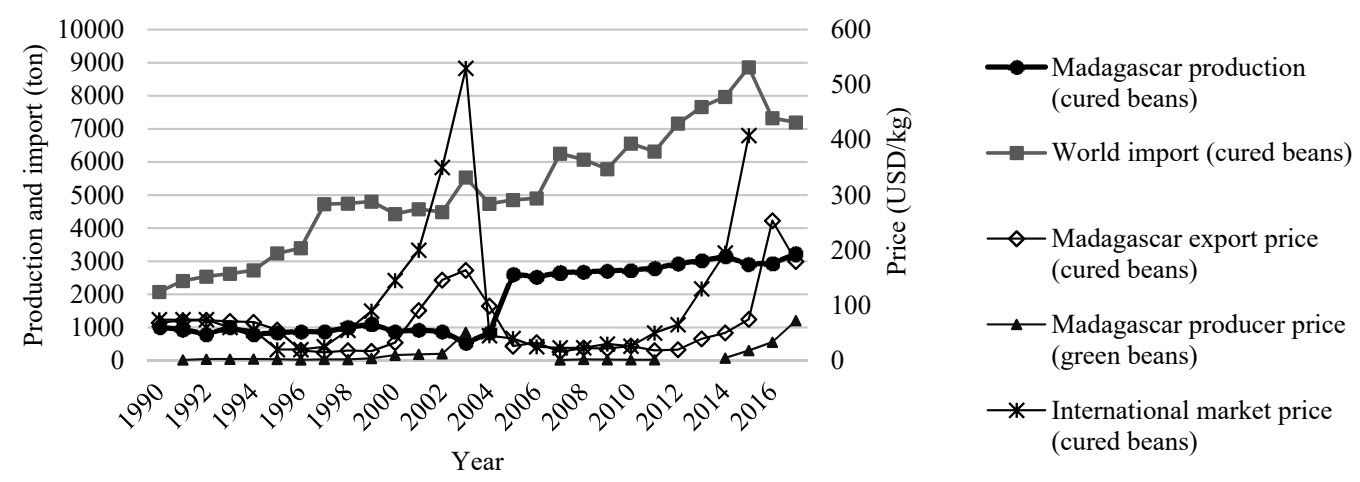

Figure 1. Vanilla demand, supply and prices, 1990-2017

Note: Data retrieved from FAOSTAT on November 19, 2019.

From 1993, structural adjustments in the vanilla sector led to the dismantling of the state marketing board and the liberalization of the market. While the local supply chain's organizational structure remained largely the same, the number of new actors in Madagascar's vanilla chain sharply increased. As of 2019, there were 138 vanilla exporters, each with its network of collectors and purchasing agents. ${ }^{9}$ ) However, outside of Madagascar, changes in the value chain took place several years later.

\section{3) Corporation-cooperative arrangements}

During the 2004-05 production year, following a price spike in 2003-04 (Figure 1), downstream lead firms (i.e., flavor processors and food corporations) began to form new sourcing channels through CCAs. Before 2004, such structures had been virtually absent in the vanilla sector (Cadot et al., 2006; Hänke et al., 2018). According to corporate publications and the author's interviews, these corporations established CCAs to source vanilla directly from producers, bypassing the commodity houses.

This study has identified five CCAs that have been created in Madagascar's vanilla value chain (Table 1), which have not been documented before to the author's best knowledge. While the list may not be exhaustive, it includes the major ones. Some of the world's leading flavor and fragrance corporations have been identified to be part of a CCA. Exceptions include Japan's Takasago International Corporation, which has an extraction plant in Madagascar but does not work with coops as of 2019. The study neither found retailers involved in a CCA even though some large European retailers report that they procure vanilla from its source. In some cases, coops participating in a CCA were created by local exporters with the support of international donor agencies or NGOs. Some coops within these CCAs were created from a pre-existing farmer association, or through a new initiative to organize farmers.

Table 1. Corporation-cooperative arrangements in Madagascar's vanilla value chain, 2019

\begin{tabular}{lllll}
\hline \multicolumn{1}{c}{ Food corporations } & Flavor processors & \multicolumn{1}{c}{ Exporters } & \multicolumn{1}{c}{ Partners and mediators } & Coops \\
\hline Unilever (Netherlands and UK) & Symrise (Germany) & none & GIZ $^{10}$, Save the Children, etc. & Various coops \\
Archer Daniels Midland (USA) & Rodelle (USA) & none & unknown & Sahanala \\
Mars (USA), Danone (France) & Firmenich (Switzerland) & Authentic & none & Savanille \\
Nestlé (Switzerland) & Givaudan (Switzerland) & Henri Fraise Fils & none & Fitama \\
Nestlé (Switzerland) & Mane (France) & Floribis & NGO Fanamby & Various coops \\
General Mills (USA) & McCormick (USA) & Ramex & NCBA-CLUSA ${ }^{11)}$ & Avotra \\
General Mills (USA) & McCormick (USA) & Biovanille & NCBA-CLUSA & Avana
\end{tabular}

Note: Data collected from the author's field research in Madagascar in 2019. All the information was triangulated with industry reports.

9) The Ministry of Industry's 2019 list of approved exporters.

10) The German International Development agency.
11) National Cooperative Business Association and Cooperative League of the United States of America. 
To unpack what a CCA entails, the paper presents the case of Symrise. This German flavor and fragrance producer was among the first to establish vanilla coops in Madagascar and has been promoting and partnering with coops on a large scale. Starting in 2006, after it had acquired a Madagascarbased export company that had already formed partnerships with farmers, Symrise began integrating 6,000 farmers via coops in their sourcing structure (Unilever, 2013). ${ }^{12)}$ Later, in 2014, when Symrise entered into a multi-stakeholder partnership with Unilever, it stated its plan to integrate an additional 4,000 farmers via 80 coops into its structure. In these arrangements, farmers are expected to comply with production requirements and quality standards set by Symrise. Farmers are monitored by the company's field representatives who work with coop leaders. Training is also provided to ensure farmers' practices meet Symrise's expectations. In return, farmers may have better access to low interest or interest-free consumption loans. They may also be eligible to obtain credit to cover expenses during the pollination period in December. This "pollination credit" incentivizes farmers to hand-pollinate according to Symrise's standards. Other incentives include health insurance, security personnel, and premiums if Fairtrade vanilla is produced.

While the implications of CCAs on farmers have yet to be explored, what has been noted is that coop members are unaware of coop laws and standards, their coop's purposes, and members' roles (Search for Common Ground Madagascar, 2017). These issues are due to the fact that the initiative to form a coop is being driven by external actors, not the coop members (ibid).

\section{Reasons for Establishing CCAs}

For flavor processors, food corporations, and retailers, securing vanilla to meet a continuously growing demand has become increasingly difficult. Another challenge is demonstrating to customers how their sourcing is ethical, sustainable, and transparent. It is in this context that buyers are keen to form relationships with coops. Here are three specific reasons that help to explain why CCAs are being created.

\section{1) Stable and long-term commodity supply}

Securing vanilla has become a challenge because the

12) https://www.unilever.com/news/news-and-features/Featurearticle/2013/Symrise-Madagascar.html accessed on July 1, 2019.

13) Symrise-Unilever Strategic Alliance brochure, May 2017.

14) Interview with exporters and importers in Madagascar in supply has not been able to keep up with the increasing demand pushing prices up. In 2017, Symrise stated that "annual fluctuations in the quantity and the quality of vanilla produced significantly affect its supply chain."13)

Figure 1 shows that vanilla demand was relatively stable between 1997 and 2006. But it almost doubled in the next decade (2007-2017). Consequently, international prices have been increasing. Cured vanilla beans cost 65 USD/kg in 2012 and reached $600 \mathrm{USD} / \mathrm{kg}$ in 2017, representing almost a tenfold increase over five years.

A reason that speaks to why natural vanilla has been so expensive can be found in the growing appetite for it. ${ }^{14)}$ Consumers' concerns about artificial flavors led to an increased demand for foods that only contain natural flavors. In response to consumer preferences, lead firms in the food and flavor industries started to look for ways to satisfy new demands, including securing stable sources of natural vanilla. Symrise, for example, traditionally a producer of synthetic vanillin, started to show interest in natural vanilla from 2005 . Later, other major companies began working with coops, especially in and after 2015, when Nestlé announced plans to go "all-natural" and eliminate artificial additives from chocolate and candy sold in the American market. Following Nestlé's announcement, other major food companies, including General Mills, Hershey's, and Kellogg's, made similar announcements, triggering demand for natural vanilla. ${ }^{15}$ ) Meanwhile, demand for sustainable products started to grow due to increasing public awareness about the social and environmental costs of producing vanilla, such as farmers' income insecurity, child labor, and deforestation (e.g., Fairfood International, 2014). For these reasons, procuring "ethical" and "sustainable" vanilla is frequently mentioned in reports released by the corporations listed in Table 1.

On the supply side, production has been stagnant, and quality has been decreasing. Following the record-high price in 2003-04, vanilla cultivation expanded. However, after prices plunged in 2005, many farmers abandoned vanilla cultivation. To recover production, it takes about four years between planting and when plants bear beans. But, considering how Madagascar's vanilla is vulnerable to diseases (e.g., fungal infection in 2008) and natural disasters

August 2019.

15) See for example, Bloomberg https://www.bloomberg.com/features/2019-economics-ofvanilla-markets-madagascar/ accessed on August 3, 2020. 
(e.g., high-category cyclones like those in 2000, 2003, and 2017), recovering production can take longer.

Quality is also a concern given the crop theft problem. Since 2014, when price again shot up, stolen unharvested vanilla beans have been found to be a significant problem. In response, some farmers harvested immature beans, which lowers vanilla quality. By forging close relationships with vanilla farmers, some corporations have provided support to farmers via coops to address this issue.

\section{2) Certifications and branding}

As label and certification initiatives, such as Fairtrade, have become more prevalent in the food industry, coops are needed to obtain some of these labels. For example, the Fairtrade Standard for Small-scale Producer Organizations, the most coveted certification in vanilla, recommends as the basic principles underlying the standard that producer organizations be composed of small-scale producers, that organizations be democratic and aim to maximize member participation and ownership. ${ }^{16)}$ It appears that among all the four legally-recognized farmer organization types in Madagascar, ${ }^{17)}$ coop aligns the closest to these principles (Search for Common Ground, 2017). It was also found that corporations gain in bettering their image by working with coops. Interviewees noted that many companies even tend to exaggerate their work with coops. ${ }^{18)}$ While that may happen, the reality is that there is a varying degree to which coops are represented in a company's procurement portfolio. For example, while coops are central to Symrise's activities in Madagascar, sourcing from coops represents a marginal but growing part of other companies' total procurement. ${ }^{19)}$

\section{3) International interests in coops and national policies for coop development}

Since the 2000s, international agencies such as the International Labour Organization (ILO) began promoting coops in developing countries, which have been seen as a "civil society driven solution to rural poverty and inequality" (Wedig, 2019). The ILO has supported several studies (e.g., Develtere et al., 2008), which have claimed that a renaissance of cooperatives is happening in Africa. In response, the ILO has been advocating for the development of new policies and programs that create an enabling environment for coops to

16) https://www.fairtrade.net/standard/spo accessed on December 2, 2019.

17) Other types of legal farmer organizations include association, groupement d'intérêt économique, and farmer union.

18) Interviews in Madagascar with heads of three different vanilla exporters and the owner and CEO of an American vanilla thrive. Alongside this, corporations engaged in contractualized agriculture in Africa started participating in donor agencies-led development initiatives to improve their image while gaining better access to low-interest loans needed to fund their operations. For instance, some financial institutions provide "green loans," which can include preferential interest rates, to companies that demonstrate active participation in sustainability-related initiatives.

The international and regional interests in coops are reflected in what has transpired in the Madagascar Symrise case over the past few years. Between 2010 and 2012, the German International Development Agency (GIZ) partnered with Symrise to train 500 vanilla farmers on sustainable agricultural practices, certification principles, and marketing. Then, from 2014, the German Ministry for Economic Cooperation and Development provided financing for the sustainable vanilla sourcing program developed by the Symrise-Unilever alliance described in Section 2.3, which involved establishing coops. In the same year, the government of Madagascar issued a decree for the practical application of the cooperative law enacted in 1999.

Coop promotion is likely one reason that explains the increasing number of coops in Madagascar. In 2005, the Ministry of Industry's registrar listed approximately 200 coops. In 2017, it contained 684 coops, with about $10 \%$ solely managing vanilla. As half of the coops do not report to the government their existence, ${ }^{20)}$ there might be roughly 150 vanilla coops with 10,000 members. It means that one out of eight vanilla farmers may already belong to a coop.

\section{Conclusion}

This study set out to identify CCAs and to describe how they have come about and why. It was revealed that CCAs are a form of vertical coordination by downstream lead firms to farmers through coops. These coops were set-up directly by, or in partnership with, other actors such as exporters and NGOs. Arrangements in the Madagascar vanilla chain are primarily led by major food and flavor corporations who seek to source vanilla beans to satisfy new consumer preferences and address societal concerns.

The main drivers for establishing these arrangements are

extract company in August 2019.

19) Ibid.

20) Results of a survey of 105 coops in February 2017. The survey was implemented mainly by the Technical Center for Agricultural and Rural Cooperation (CTA) and the NCBACLUSA. 
similar to the reasons why firms promote CFAs, as identified by the contract farming literature, which include risk and reputation management. From the firm's perspective, managing risks associated with harvest failure or lower quality is essential in vanilla production. My research supports previous findings that indicate how global firms tend to favor implicit contracts to spot markets given the market risks in the form of price volatility (e.g., Reardon and Barrett, 2000). This study also confirms how firms invest in new market niches, such as Fairtrade, that promote smallholders' inclusion (Oya, 2012). Lastly, this study shows how coops are the preferred producer organization as they are closely associated with the social and solidarity economy, which has become essential for an increasing number of consumers (Wedig, 2019).

While the motives for creating CCAs complement some of the CFAs' objectives, I suggest that CCAs be examined as exogenous of CFA-centric discussions to disentangle the relations between actors and to ask specific questions about the coops and farmers involved. Doing so may create new lines of inquiry from other fields, such as cooperative studies, that have examined coops in developing countries but have yet to identify CCAs. Focusing on the relations within these arrangements seems essential given the concerns raised about the asymmetrical power relations and uneven distribution of risks between producers and buyers in CFAs and calls to balance producer-buyer relationships (e.g., Bijman, 2008). Thus, the relational dimension should be embedded in future studies on CCAs.

Acknowledgment: This research is partly funded by the Japan Society for the Promotion of Science (JSPS) KAKENHI grant no. $18 \mathrm{~K} 05847$.

\section{References}

Barrett, C. B., M. E. Bachke, M. F. Bellemare, H. C. Michelson, S. Narayanan, and T. F. Walker (2012) Smallholder Participation in Contract Farming: Comparative Evidence from Five Countries, World Development 40 (4): 715-730. https://doi.org/10.1016/j.wo rlddev.2011.09.006.

Bijman, J. (2008) Contract farming in developing countries: An overview of the literature, Working paper, Wageningen University and Research, Department of Business Administration.

Birchall, J. (1997) The International Cooperative Movement, Manchester University Press, Manchester, UK; New York.

Blarel, B. and D. Dolinsky (1994) Market Imperfections and Government Failures: The Vanilla Sector in Madagascar, in S.
Jaffee and J. Morton, eds., Marketing Africa's High-Value Foods: Comparative Experiences of an Emergent Private Sector, Kendall Hunt Publishing Company, 255-318.

Cadot, O., L. Dutoit, and J. De Melo (2006) The elimination of Madagascar's vanilla marketing board, ten years on, Policy Research Working Paper No. 3979, Washington, DC: World Bank. Correll, D. (1953) Vanilla - Its Botany, History, Cultivation and Economic Import, Economic Botany 7: 291-358. https:/doi.org/ 10.1007/BF02930810.

Develtere, P., I. Pollet, and F. O. Wanyama, eds. (2008) Cooperating out of Poverty: The Renaissance of the African Cooperative Movement, Geneva: International Labor Office.

Fairfood International (2014) Recipe for Change: The Need for Improved Livelihoods of Vanilla Farmers in Madagascar.

Friedland, W. H., A. E. Barton, and R. J. Thomas (1981) Manufacturing Green Gold, Cambridge University Press.

Gereffi, G., J. Humphrey, and T. Sturgeon (2005) The Governance of Global Value Chains, Review of International Political Economy 12 (1): 78-104. https://doi.org/10.1080/096922905000 49805.

Gibbon, P. and S. Ponte (2005) Trading Down: Africa, Value Chains, and the Global Economy, Philadelphia, PA: Temple.

Hänke, H., J. Barkmann, L. Blum, Y. Franke, D. A. Martin, J. Niens, K. Osen, V. Uruena, S. A. Witherspoon, and A. Wurz (2018) Socio-economic, land use and value chain perspectives on vanilla farming in the SAVA Region, DARE Discussion Papers 1806, Georg-August University of Göttingen.

International Labour Organization (2012) Report on the Existence of Child Labor in the Vanilla Sector in the SAVA Region, Antananarivo: ILO.

Little, P. D. and M. J. Watts, eds. (1994) Living under Contract: Contract Farming and Agrarian Transformation in sub-Saharan Africa, University of Wisconsin Press.

Oya, C. (2012) Contract Farming in sub-Saharan Africa: A Survey of Approaches, Debates and Issues, Journal of Agrarian Change 12 (1): 1-33. https://doi.org/10.1111/j.1471-0366.2011.00337.x.

Reardon, T. and C. B. Barrett (2000) Agroindustrialization, Globalization, and International Development: An Overview of Issues, Patterns, and Determinants, Agricultural Economics 23: 195-205. https://doi.org/10.1111/j.1574-0862.2000.tb00272.x.

Search for Common Ground Madagascar (2017) Institutional Analysis of Farmer Organizations in the Vanilla Sector, Report for the Strategic Alliance Symrise-Unilever-GIZ.

Wedig, K. (2019) Cooperatives, the State, and Corporate Power in African Export Agriculture: The Case of Uganda's Coffee Sector, Abingdon: Routledge.

World Bank (2007) Agriculture for Development: World Development Report 2008. Washington, DC: The World Bank. 